\title{
Public Health and Disability: A Real-Life Example of the Importance of Keeping Up the Good Work
}

\author{
Ann I. Alriksson-Schmidt * and Gunnar Hägglund \\ Lund University, Skåne University Hospital, Department of Clinical Sciences Lund, Orthopedics, \\ 22185 Lund, Sweden; gunnar.hagglund@med.lu.se \\ * Correspondence: ann.alriksson-schmidt@med.lu.se
}

check for updates

Citation: Alriksson-Schmidt, A.I.; Hägglund, G. Public Health and Disability: A Real-Life Example of the Importance of Keeping Up the Good Work. Disabilities 2021, 1, 151-160. https://doi.org/10.3390/disabilities 1030012

Academic Editor: Reinie Cordier

Received: 4 March 2021

Accepted: 1 July 2021

Published: 7 July 2021

Publisher's Note: MDPI stays neutral with regard to jurisdictional claims in published maps and institutional affiliations.

\begin{abstract}
Secondary and tertiary prevention strategies are essential in targeting those with disabilities to improve their health and well-being. In Sweden, over 95\% of all children with cerebral palsy (CP) participate in a follow-up program in which one of the goals is to prevent hip dislocations. To demonstrate the importance of maintaining timely, systematic, preventive, work overtime, we reviewed the incidence of hip dislocations from 2010 to 2019 and the number of children who underwent different types of hip surgeries in Sweden. Leading to 2015 , the number of hip dislocations reduced from $8.8 \%$ before the introduction of the program to $0.3-0.4 \%$, followed by a gradual increase to $0.8 \%$ in 2019 . The proportion of children who underwent adductor-psoas lengthening as their primary preventative surgery decreased from $65 \%$ in 2010 to $45 \%$ in 2019 , with a corresponding increase of children undergoing femoral osteotomy, indicating that more children underwent surgery at a later stage. One of the likely reasons for the increase in hip dislocations includes longer waiting periods before surgery, possibly due to a shortage of nurses. At least seven of the 29 children with dislocated hips waited more than one year for preventative surgery and developed a hip dislocation during this period. It is also possible that the increased number of children with hip dislocations may be associated with the fact that more children with $\mathrm{CP}$ have immigrated to Sweden in recent years without receiving corresponding compensation in healthcare resources. The results highlight the importance of constantly monitoring follow-up programs to swiftly notice alarming trends that require immediate action.
\end{abstract}

Keywords: disability; quality of life; cerebral palsy; surveillance

\section{Introduction}

All children have the right to health and suitable quality of life (QoL) [1]. However, disability, irrespective of which of the numerous available definitions are used, affects millions of people of all ages. These individuals are at an increased risk of reduced participation, limited involvement in everyday activities, and reduced QoL [2,3]. This may be due to any combination of body function and structure, personal factors, or notably the environment, as identified in the World Health Organization's (WHO) International Classification of Functioning, Disability, and Health [4]. Worldwide, individuals with disabilities are among the most marginalized in society, with less access to education, work, and financial assets [5].

Similar to disability, public health is defined in many different ways. The definition used by the American Public Health Association states that "public health promotes and protects the health of people and the communities where they live, learn, work and play" [6]. In contrast to regular healthcare practices, which targets unique individuals and performs in reactive manner, public health is concerned with population-based health with a focus on prevention. In brief, public health sectors use surveillance to investigate the scale of a problem; regarding epidemiology, these sectors identify specific groups, develop measures, apply rigorous research methods, and implement interventions to improve health 
outcomes [7]. Traditionally, public health has been charged with preventing morbidity, mortality, and disability [8]. Given the broad heterogeneity of disability, combined with the goal of preventing it, there has been confusion as to where those with disabilities fit into the context of public health $[7,9]$. This could partially be explained by the inaccuracy of equating disability with poor health [7]. Nevertheless, primary, secondary, and tertiary prevention are all cornerstones of public health and the need for and importance of secondary and tertiary prevention strategies targeting those living with disabilities must not be understated. In Sweden, a public health population-based initiative for children with cerebral palsy (CP) was launched nationwide in 2005.

\subsection{Cerebral Palsy and the Cerebral Palsy Follow-Up Program (CPUP)}

$\mathrm{CP}$ is one of the most common lifelong disabilities worldwide, caused by nonprogressive brain damage that occurs before the age of two years [10], oftentimes already present in utero. There is great variability in functioning, however, motor function is always affected and challenges in cognition, perception, sensation, behavior, and comorbidities such as epilepsy are frequent $[10,11]$. Hip displacement, during which the femoral head is laterally displaced within the joint, is common in individuals with $\mathrm{CP}$ due to altered muscle forces across the hip joint. Hip dislocation is a severe problem with a high risk of pain, development of severe contractures, windswept deformity, and scoliosis (Figure 1), resulting in problems with posture, sitting, standing, and walking $[12,13]$. The risk of hip dislocation is estimated to be within $15-20 \%$ of the total population of individuals with $\mathrm{CP}$ and the risk is highest in those with severe limitations of gross motor function [14]. Hip dislocation in $\mathrm{CP}$, though, is often preventable. Evidence demonstrates that at a population-based level, hip displacement can be prevented if young children with $\mathrm{CP}$ are included in surveillance and follow-up programs that include repeated radiographic and clinical examinations and preventative treatments for hip displacement $[15,16]$. Non-surgical management to prevent hip dislocation includes the positioning of the hip in abduction and extension when lying, sitting, and standing. Surgical treatments of hip displacement in $\mathrm{CP}$, however, consist of adductor-iliopsoas lengthening (APL) or varus derotation osteotomy of the proximal femur (VDRO) and sometimes in combination with pelvic osteotomy. APL is performed primarily on younger children with a lesser degree of displacement, while osteotomy is performed on children with a more severe displacement. The results of APL may also be an indicator of how long the hip displacement was allowed to continue.

The cerebral palsy follow-up program (CPUP) began in 1994 in the region of Skåne in southern Sweden to address the problem of painful hip dislocations in children with $\mathrm{CP}$ [17]. The children with $\mathrm{CP}$ who attended the clinic experienced painful and difficult to treat hip dislocations requiring extensive surgery. In some cases, it was too late to perform surgery at all. The multidisciplinary team at the time, consisting of a pediatric orthopedic surgeon (author GH), physical therapist, pediatric neurologist, and in collaboration with the professionals at the child rehabilitation units, decided to adopt a multidisciplinary preventative approach to prevent hip dislocations. The purpose of this decision was to create and implement a population-based follow-up program where all consenting children with a suspected or confirmed diagnosis of $\mathrm{CP}$ would be monitored over time, irrespective of indications of hip dislocation. Standardized assessments were developed and the data collected were compiled into a secure database. Currently, 95\% of all children, adolescents, and adults with CP in Sweden participate in the CPUP. Given that the CPUP began in southern Sweden in the 1990s, we have access to a pre-CPUP cohort of individuals consisting of those born 1990-1991, constituting a historical pre-surveillance cohort. Moreover, inclusion of those born in 1992 or later were monitored through the surveillance program. Results from the program were published after 10 and 20 years, demonstrating that hip dislocations in children with CP reduced from $8.8 \%$ to $0.4-0.3 \%[15,16]$. Given the longevity of the CPUP, the program can be considered an exemplar of a public health disability program and thus requires quality assurance monitoring alike to other programs. The 
monitoring can be accomplished by analyzing the trajectory of hip dislocations in children with CP in Sweden over the course of ten years.

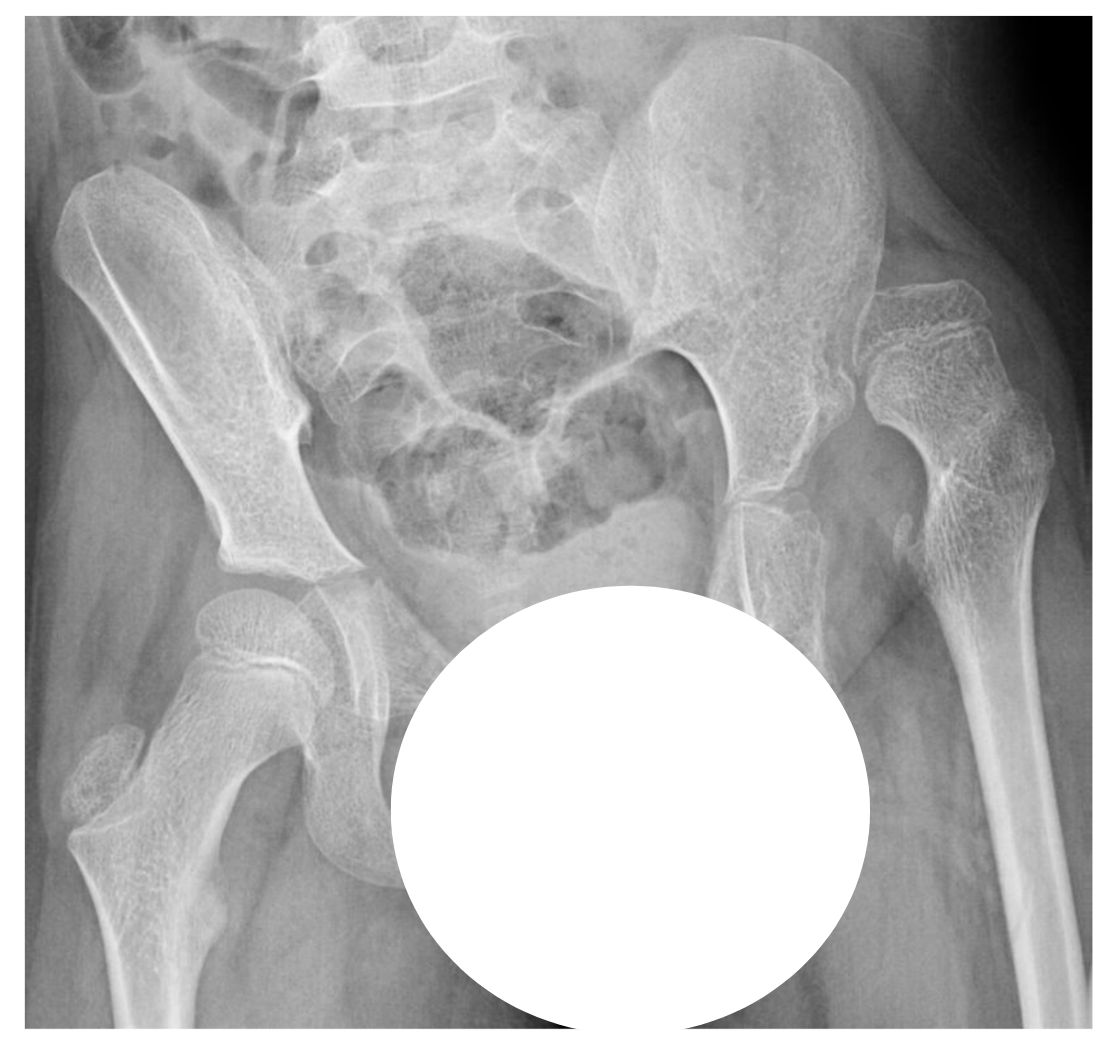

Figure 1. Pelvic radiograph of an eight-year old boy with cerebral palsy, left-sided hip dislocation, and pelvic obliquity.

\subsection{Purpose and Aims}

The overall purpose of this report was to broadly discuss the importance of vigilant prevention programs for individuals with disabilities. This was accomplished by showcasing a real-life example of a well-established population-based follow-up program for individuals with CP. More specifically, we

1. studied the incidence of hip dislocations in children with CP residing in Sweden from 2010 to 2019 ,

2. reviewed the number of children who underwent APL and VDRO during 2010-2019,

3. reviewed two possibly related hypotheses which might be associated with the development of hip dislocations in children with $\mathrm{CP}$ over time, and

4. discussed the significance of well-functioning infrastructure and adherence over time in public health.

\section{Materials and Methods}

This was a retrospective registry study based on data from the CPUP and Statistics Sweden. In the CPUP, the gross motor function is classified by the internationally used Gross Motor Function Classification System (GMFCS); this system is a five-level scale in which level I represents the highest level and level $\mathrm{V}$ represents the lowest level of gross motor function $[18,19]$. All children up to 8 years of age within the GMFCS levels III-V are radiographically examined with a pelvic anteroposterior view annually and those within the GMFCS level II at 2 and 6 years of age. Children in level I are not examined radiographically provided that the child has a normal pain-free range of hip motion. After 8 years of age, the examination intervals are determined individually based on the results of previous examinations and clinical reports. The degree of displacement of the femoral 
head is measured with the Reimer's Migration Percentage (MP), where MP 100\% defines hip dislocation (Figure 2).

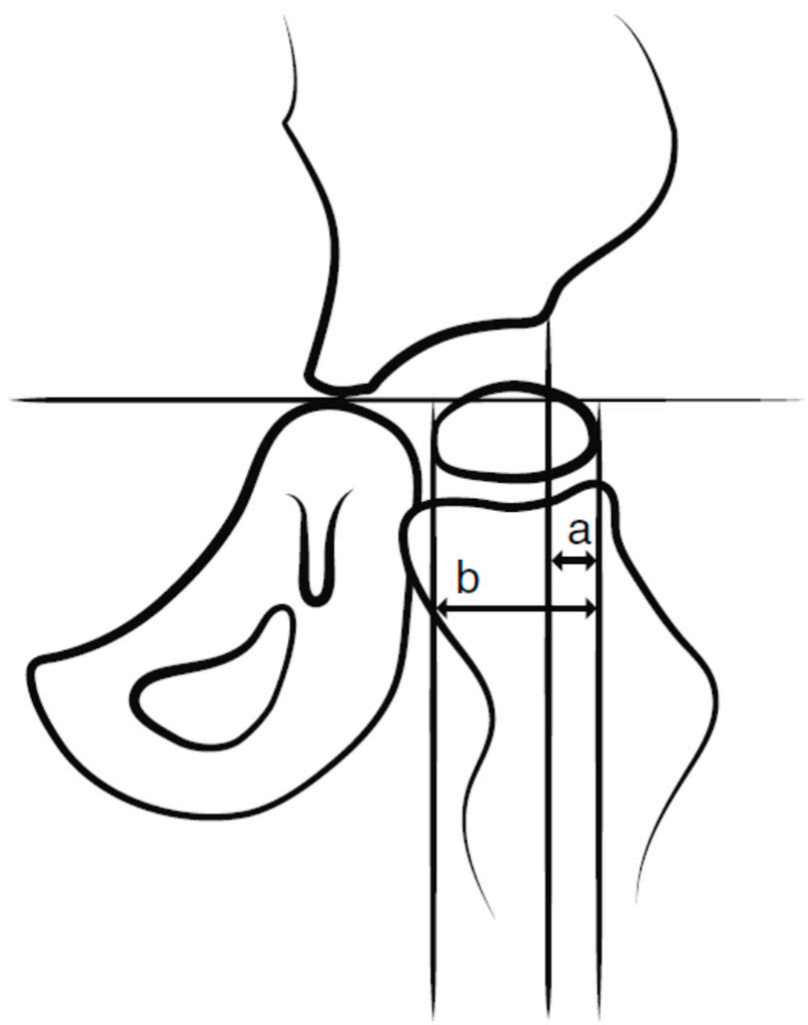

Figure 2. Measurement of hip migration percentage $(M P) . M P=a / b \times 100$.

Children 16 years or younger with a diagnosis of CP in GMFCS levels I-V that were reported to the CPUP were included. Children entering the program with hip dislocation (MP 100\%) recorded on the first radiographic examination were excluded from the analyses.

\section{Statistics}

The number of individuals with a recorded hip dislocation as of 31 December, for each individual year during 2010-2019, was registered and related to the total number of children in each respective GMFCS level during the same time span. Historical comparisons were made with the results from the control group of children born between 1990-1991 (before the CPUP) and with the results presented after the 10 and 20-year follow-ups of the CPUP. In addition, we assessed the number of children with a diagnosis of CP in the CPUP who were born abroad during the same time period and their respective GMFCS-level. Data were presented descriptively as absolute numbers and percentages. The proportion of children who underwent surgery to prevent hip dislocation through APL and VDRO was registered for the years 2010-2019.

This study received approval from the Ethics Board LU-433-99 (reference number 2020 04511).

\section{Results}

The total number of children with CP in the CPUP increased from 2186 in 2010 to 3791 in 2019. The distributions according to sex and GMFCS levels during the years of interest were similar. The mean age increased from 7.3 years in 2010 to 9.6 years in 2019 (Table 1). 
Table 1. Sex, Gross Motor Function Classification System (GMFCS) level, and mean age of participants from 2010-2019.

\begin{tabular}{|c|c|c|c|c|c|c|c|c|c|c|}
\hline \multirow[t]{2}{*}{ Variable } & \multicolumn{10}{|c|}{ Report Year } \\
\hline & 2010 & 2011 & 2012 & 2013 & 2014 & 2015 & 2016 & 2017 & 2018 & 2019 \\
\hline Boys (\%) & $\begin{array}{l}1253 \\
(57.3)\end{array}$ & $\begin{array}{l}1388 \\
(57.1)\end{array}$ & $\begin{array}{l}1530 \\
(57.1)\end{array}$ & $\begin{array}{l}1654 \\
(56.9)\end{array}$ & $\begin{array}{l}1797 \\
(56.9)\end{array}$ & $\begin{array}{l}1928 \\
(57.2)\end{array}$ & $\begin{array}{l}2021 \\
(57.2)\end{array}$ & $\begin{array}{l}2078 \\
(57.3)\end{array}$ & $\begin{array}{l}2155 \\
(57.7)\end{array}$ & $\begin{array}{l}2206 \\
(58.2)\end{array}$ \\
\hline Girls (\%) & $919(42.0)$ & $\begin{array}{l}1028 \\
(42.3)\end{array}$ & $\begin{array}{l}1133 \\
(42.3)\end{array}$ & $\begin{array}{l}1233 \\
(42.4)\end{array}$ & $\begin{array}{l}1336 \\
(42.3)\end{array}$ & $\begin{array}{l}1429 \\
(42.4)\end{array}$ & $\begin{array}{l}1486 \\
(42.0)\end{array}$ & $\begin{array}{l}1514 \\
(41.8)\end{array}$ & $\begin{array}{l}1549 \\
(41.4)\end{array}$ & $\begin{array}{l}1569 \\
(41.4)\end{array}$ \\
\hline $\begin{array}{l}\text { Unknown } \\
(\%)\end{array}$ & $14(0.6)$ & $15(0.6)$ & $17(0.6)$ & $22(0.8)$ & $27(0.9)$ & $26(0.8)$ & $28(0.8)$ & $32(0.9)$ & $34(0.9)$ & $16(0.4)$ \\
\hline Total & 2186 & 2431 & 2680 & 2909 & 3160 & 3373 & 3535 & 3624 & 3738 & 3791 \\
\hline $\begin{array}{l}\text { GMFCS I } \\
(\%)\end{array}$ & $930(42.5)$ & $\begin{array}{l}1042 \\
(42.9)\end{array}$ & $\begin{array}{l}1154 \\
(43.1)\end{array}$ & $\begin{array}{l}1236 \\
(42.5)\end{array}$ & $\begin{array}{l}1364 \\
(43.2)\end{array}$ & $\begin{array}{l}1488 \\
(44.1)\end{array}$ & $\begin{array}{l}1549 \\
(43.8)\end{array}$ & $\begin{array}{l}1599 \\
(44.1)\end{array}$ & $\begin{array}{l}1678 \\
(44.9)\end{array}$ & $\begin{array}{l}1703 \\
(44.9)\end{array}$ \\
\hline II (\%) & $322(14.7)$ & 354 (14.6) & $403(15.0)$ & 454 (15.6) & $503(15.9)$ & $540(16.0)$ & $574(16.2)$ & $570(15.7)$ & $563(15.1)$ & $\begin{array}{l}598 \\
(15.8)\end{array}$ \\
\hline III (\%) & 185 (8.5) & $220(9.0)$ & $236(8.8)$ & $263(9.0)$ & 275 (8.7) & $286(8.5)$ & $320(9.1)$ & $330(9.1)$ & 335 (9.0) & $\begin{array}{l}327 \\
(8.6)\end{array}$ \\
\hline IV (\%) & $296(13.5)$ & $342(14.1)$ & $386(14.4)$ & $424(14.6)$ & $450(14.2)$ & $482(14.3)$ & $524(14.8)$ & $517(14.3)$ & $529(14.2)$ & $\begin{array}{l}527 \\
(13.9)\end{array}$ \\
\hline $\mathrm{V}(\%)$ & $332(15.2)$ & $383(15.8)$ & 421 (15.7) & 458 (15.7) & $507(16.0)$ & $548(16.2)$ & $568(16.1)$ & $608(16.8)$ & 633 (16.9) & $\begin{array}{l}636 \\
(16.8)\end{array}$ \\
\hline $\begin{array}{l}\text { Unclassified } \\
(\%)\end{array}$ & $121(5.5)$ & $90(3.7)$ & $80(3.0)$ & $74(2.5)$ & $61(1.9)$ & $39(1.2)$ & $0(0)$ & $0(0)$ & $0(0)$ & $0(0)$ \\
\hline Mean age & 7.3 & 7.6 & 7.9 & 8.3 & 8.7 & 9.0 & 9.3 & 9.4 & 9.5 & 9.6 \\
\hline
\end{tabular}

The total number of children with hip dislocation ranged from 12 to 14 during the years 2010-2014 (0.4-0.5\%). Beginning in 2015, the number gradually increased over time, reaching 29 in 2019 (0.8\%) (Figure 3). Of the 29 children with hip dislocations in 2019, four experienced hip dislocations while waiting for spine surgery to address their condition of scoliosis, which were to be performed prior to the hip surgery. An additional three children dislocated their hips while wait-listed for hip surgery. For some of these children, reductions of the dislocated hips are planned and for one child, a salvage procedure will have to be undertaken. Of the remaining 22 children with hip dislocations, eight were in such poor health that preventative surgery was deemed not possible; in four cases the families refused surgery; in two cases the hip re-dislocated after failed surgery; and in the remaining eight cases the reasons why the hip was not operated on are unknown.

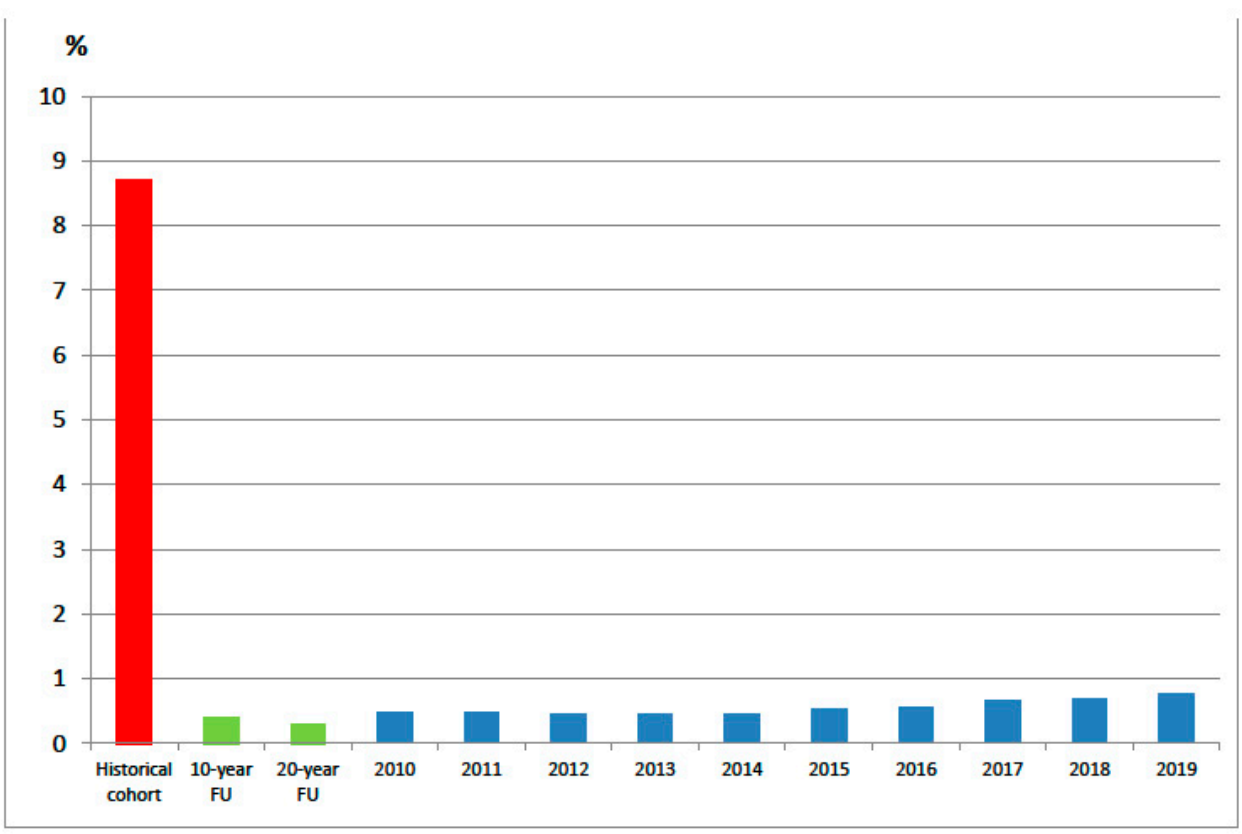

Figure 3. Proportion of children with cerebral palsy and hip dislocations during the years 2010-2019. For comparison, a historic cohort before the CPUP (birth years 1990-1991) and 10 and 20-year follow-ups are shown. 
The proportion of children who underwent APL as their primary surgery decreased from $65 \%$ in 2010 to $45 \%$ in 2019 with a corresponding increase of children operated with VDRO (Figure 4).

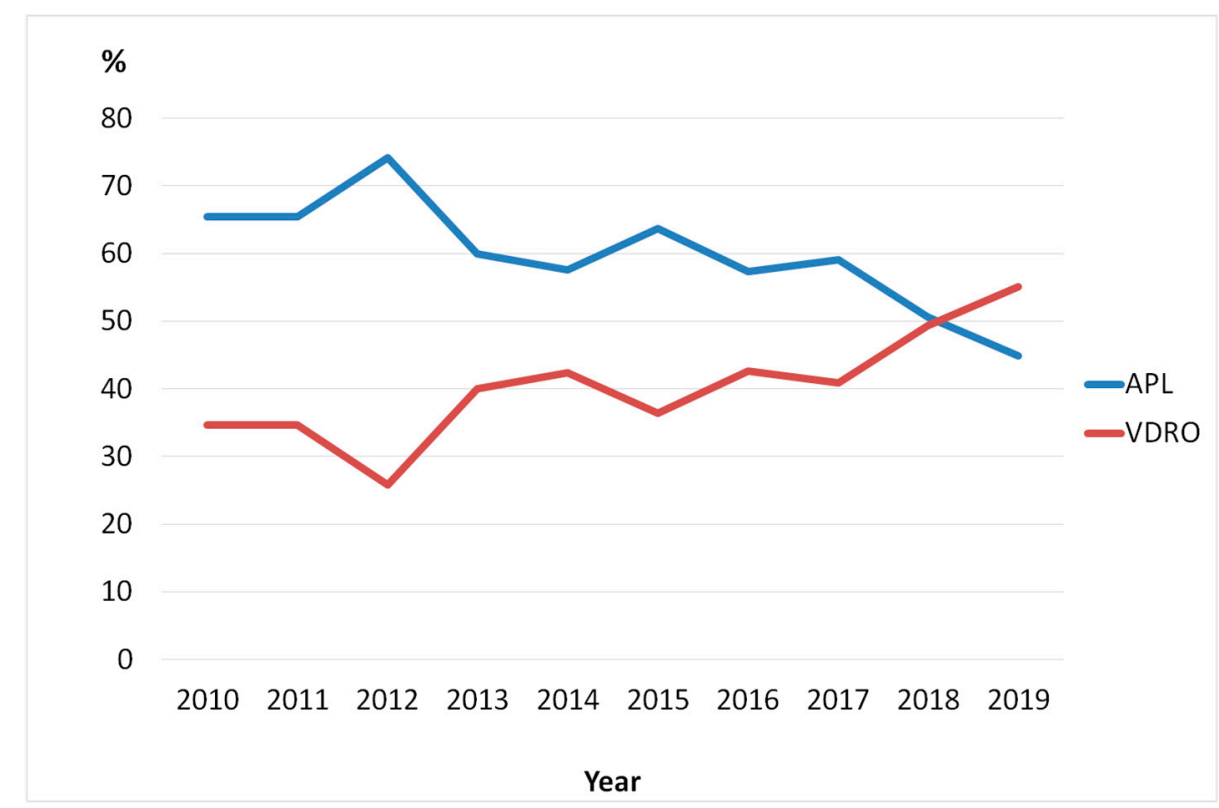

Figure 4. Proportion of children who underwent surgery with adductor-iliopsoas lengthening (APL) and varus derotation osteotomy (VDRO) during the years 2010-2019.

Results indicate that the fact surgeries were performed at a later stage may be related to why hip dislocations are on the rise in the pediatric population with $\mathrm{CP}$ in Sweden. Another possible explanation may be that Sweden has more recently experienced an influx of children with $\mathrm{CP}$ born abroad and that these children are potentially more likely to be in the GMFCS levels IV-V, therefore at an increased risk of hip dislocation. In Figure 5, we present the distribution of children ages 0-16 years old born in Sweden versus born abroad and in Figure 6, the GMFCS distribution of children born in Sweden versus born abroad.

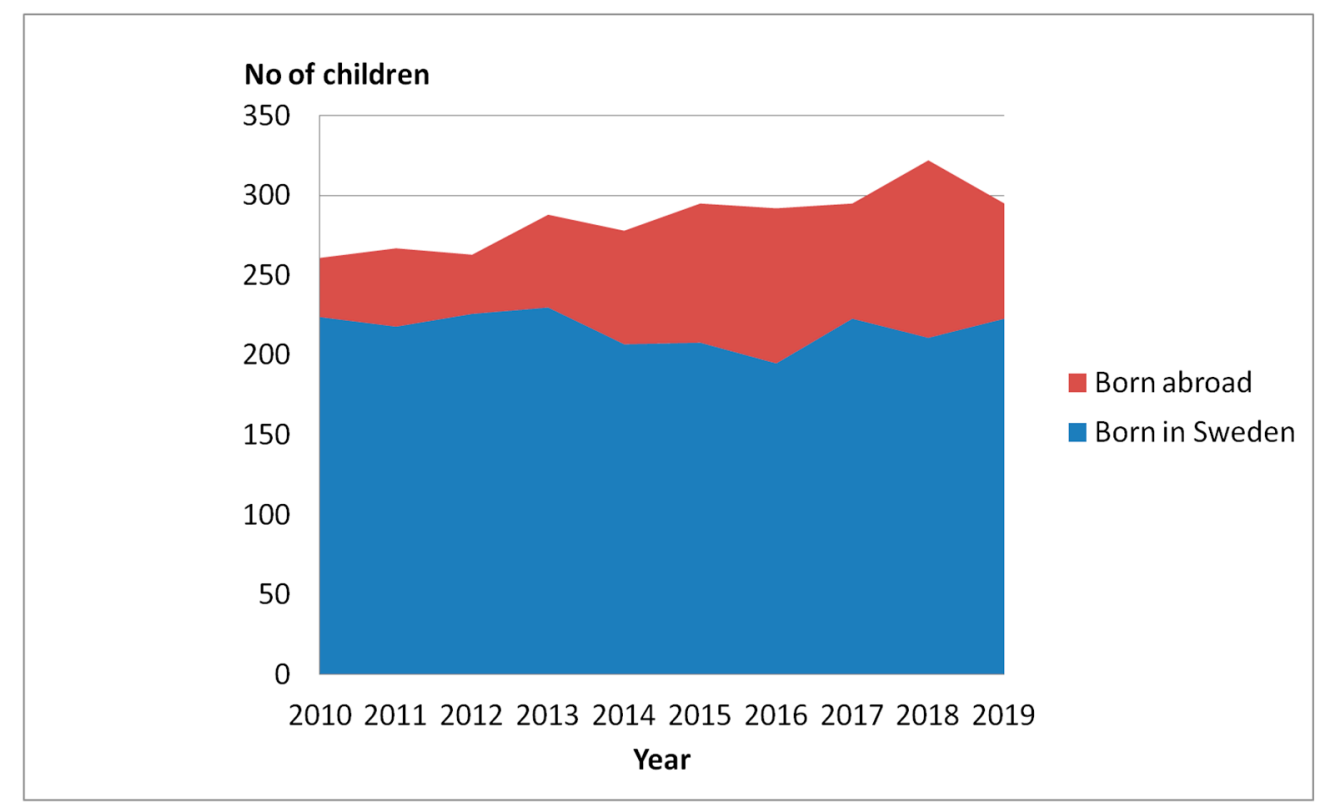

Figure 5. Number of additional children with cerebral palsy who have joined the CPUP, 0-16 years of age, born in Sweden versus born abroad included in CPUP during the years 2010-2019. 


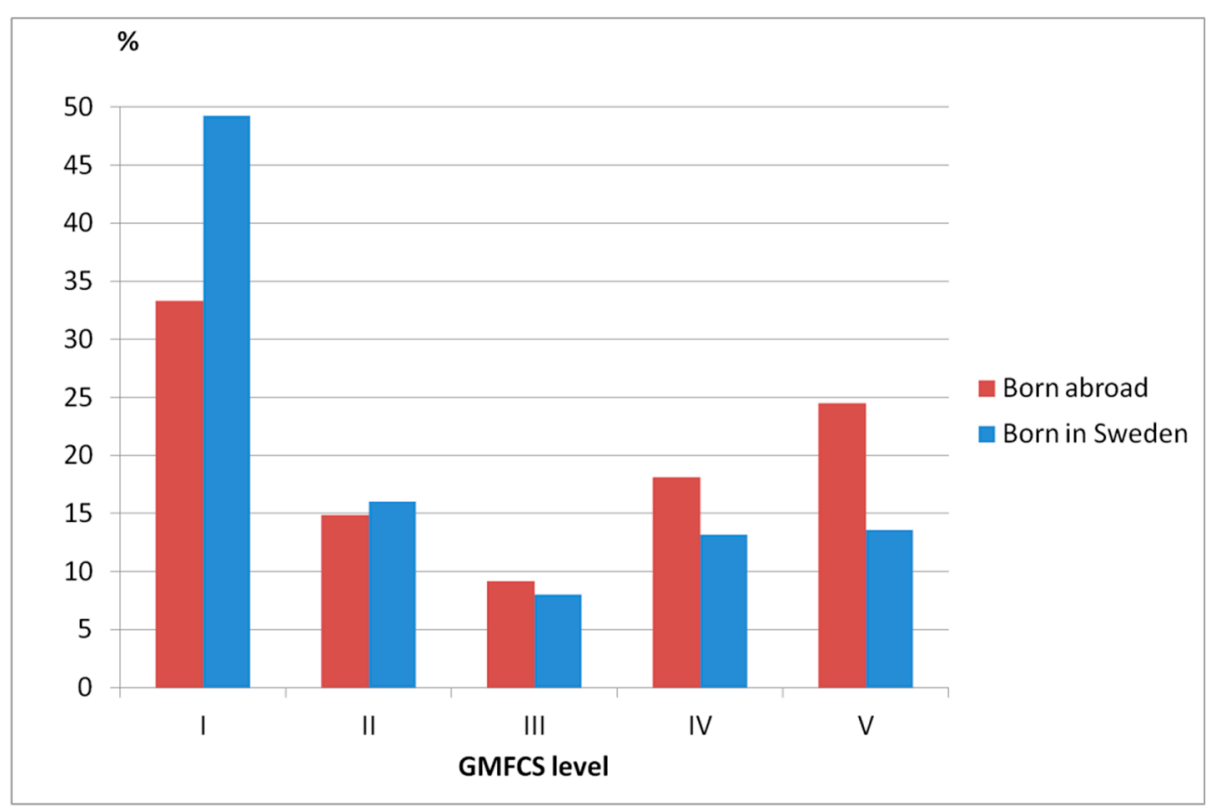

Figure 6. The Gross Motor Function Classification System (GMFCS) distribution of children with cerebral palsy born in Sweden versus born abroad.

\section{Discussion}

Secondary and tertiary prevention efforts are important for all, including individuals with disabilities. Hip dislocation is a secondary condition that primarily affects individuals with CP in the GMFCS levels III-V. Dislocations tend to be painful and are often indirectly negatively associated with QoL. Our earlier findings have demonstrated that hip dislocations can be reduced substantially through surveillance and systematic preventative follow-ups $[15,16]$. The current report illustrates that an increase of hip dislocations in children with CP in Sweden has occurred in the last five years. Internationally, a total of $0.8 \%$ of hip dislocations in children with $\mathrm{CP}$ is still a low percentage. However, this indicates that a number of young children may have experienced avoidable pain, reduced function, possibly permanently, likely have had to undergo more invasive surgeries, and have had longer rehabilitation periods than otherwise necessary. Healthcare practice has operated more successfully in the past, thus it can be achieved in the present.

The pillars of public health relevant to this study include surveillance, epidemiology, and interventions, all of which play an essential part; to ensure the prevention of hip dislocations over time requires all three. By monitoring hip dislocations in the CPUP, it is clear that the incidence of hip dislocations is headed in the wrong direction. To implement an intervention to stabilize the incidence of hip dislocations, it is necessary to determine the reasons why it is happening in the first place. One important question to address is whether the observed increase is real. At times, changes in the prevalence or presence of incidence is artificial and due to, for instance, a change in a definition or criteria. The definition of CP was expanded upon in 2007 [10], before the time period of the current study. However, it did not change the prevalence of individuals with $\mathrm{CP}$ enrolling in the CPUP. Furthermore, the definition of hip dislocations used in the CPUP has remained constant, as have the assessment intervals; thus, it is unlikely that hip dislocations are more likely to be detected now than previously for this reason.

The total number of children in the surveillance program increased during the study period. Most regions included children born in 2000 and later, which indicates that the proportion of children aged 10-16 years gradually increased during the years 2010-2016, accounting for the higher mean age in recent years. Most hip dislocations occur before the age of 10 years [14], indicating that most likely this did not affect the reported proportion of children with hip dislocations during these years. It is also possible that the increased number of children during the years 2015-2019 was due to an influx of children with 
$\mathrm{CP}$ who immigrated to Sweden on account of international crises. These children were more likely to be in the GMFCS levels IV-V and thus had a higher risk of hip dislocation. Nevertheless, the distribution of the GMFCS levels in the total population was stable during these years. However, the analyses did not include children who had a complete dislocation (MP 100\%) on arrival to Sweden. Children in the study cohort who had immigrated to Sweden also had the opportunity to be monitored and treated to prevent hip dislocation, alike to children born in Sweden. Although this may sound equitable and fair, there are obstacles that might prevent this from actually happening. Immigrating to a new country can be tumultuous and it is notably difficult to learn a new country's healthcare system, particularly if there are language barriers. Hence, it is possible that it takes a longer time for children with $\mathrm{CP}$ who have immigrated to Sweden more recently to become part of CPUP than children born in Sweden. Consequently, the MPs might increase without notice, resulting in hip dislocations. Furthermore, the available medical resources have not experienced an increase sufficient to meet the demands of the increased number of children requiring services.

The procedure of preventing hip dislocations must be established and the importance of timing is vital. The families of children with CP must be systematically scheduled and are required to meet appointment times in order to obtain success. Physical therapists must measure, record (surveillance), and intervene if necessary. When problems arise, swift referrals must be sent to an orthopedist who can decide on what actions need to be taken. It is possible that interventions or surgeries are delayed due to waiting lists and delayed surgeries, allowing emerging hip displacements to become hip dislocations. Sweden is a small country and there are not many orthopedists who work with children with $\mathrm{CP}$. Therefore, this should be considered and investigated as a potential contributing cause of hip dislocations. Of the 29 children with hip dislocations in 2019, seven dislocated while on the waiting list for spine or hip surgery. Some of the children with hip dislocations were considered too weak to undergo surgery and in some cases the parents chose to refrain from surgery. However, the proportion of children who do not undergo preventative surgery have routinely not increased over the years. There is a well-known shortage of nurses in Sweden which has resulted in increased waiting times for surgery at several hospitals. In recent years, the proportion of children who have undergone APL surgery has decreased, while the proportion that have undergone VDRO surgery has increased, indicating that children are undertaking surgeries at later ages. Terjesen analyzed a hip surveillance program in parts of Norway; hip dislocation occurred in $4 \%$ of the children in the program. The main reasons noted for the occurrence of hip dislocation were late inclusion in the program and long waiting lists for preventative surgery [20], which supports the hypotheses regarding why we are observing an increase in hip dislocations in Sweden.

These issues also must be seriously considered in light of the foreseeable delay in many healthcare services that can be expected due to COVID-19, although the data presented herein were gathered prior to the onset of the pandemic. There is also the importance of collective memory among professionals in public health. For instance, healthcare professionals working when poliomyelitis was rampant and could observe the consequences first-hand likely understood the importance of population-based vaccination programs better as a result of the experience. Thus, healthcare staff in Sweden, including clinic supervisors, who regularly work with children that are in obvious pain due to hip dislocations may be more likely to understand the importance of establishing a multidisciplinary infrastructure and that fast intervention is crucial. Newer staff may be unaware of the negative outcomes that can result when hip dislocations are not prevented. We intend to investigate this question further and evaluate whether there is a need for additional training or education regarding the importance of timely intervention. It should be noted that this is a hypothesis and we do not have access to data validating that this is actually the case. The successful prevention of hip dislocations requires knowledge and action on many levels, including from those who are in administrative positions and make policy or decisions that affect healthcare. 
Several measures have already been administered to halt the increasing proportion of children with CP and hip dislocation. A survey sent to orthopedic surgeons in Sweden confirmed that waiting times for back surgery vary substantially between different clinics. This has been brought to the attention of the pediatric orthopedic surgeons and other healthcare professionals in Sweden to communicate that various measures can be taken locally to prioritize these children for surgery and to encourage the referral to hospitals that have shorter waiting lists for surgery. In the next few years, we will be able to analyze whether these efforts have been sufficient to reduce the increasing incidence of hip dislocations in this population. This effort may be especially important during the COVID-19 pandemic as there is a risk that waiting times will increase even further. This also applies to other services and populations, and it is crucial that healthcare services are carefully prioritized during and following the pandemic to minimize the potential long-reaching ramifications of COVID-19. More information on these matters are also planned to be given to families of children with CP.

People with disabilities require effective systems in place to monitor their health and well-being. In this report, we have used the real-life example of hip dislocations of children with CP in Sweden. Nevertheless, our message can apply to any of number of healthcare topics. In the case of the CPUP, we have demonstrated that through the hard work of the professionals involved in the healthcare of children with $\mathrm{CP}$, it is possible to reduce the number of hip dislocations. However, the importance of monitoring changes over time, or surveying the surveillance, determining facilitators and barriers, and acting upon alarming trends are central to the idea of keeping up the good work.

\title{
5. Limitation
}

Alike to others, this study has limitations. Our study is limited in terms of sources; for instance, our conclusions would be strengthened if we had greater access to information on the resources allocated to the habilitation centers over time, as well as the actual reasons for delay of surgery for all of the years included.

Author Contributions: Conceptualization, A.I.A.-S. and G.H.; Writing—original draft, A.I.A.-S.; Writing-review \& editing, A.I.A.-S. and G.H. Both authors have read and agreed to the published version of the manuscript.

Funding: This project was supported by grants from the Swedish Research Council for Health, Working Life, and Welfare (2018-01468) and from Stiftelsen för Bistånd åt Rörelsehindrade i Skåne.

Institutional Review Board Statement: The study was conducted according to the guidelines of the Declaration of Helsinki, and approved by the Ethics Committee of Lund University (LU-433-99, \# 2020 04511).

Informed Consent Statement: Oral consent is required to participate in CPUP.

Data Availability Statement: Contact the authors for more information.

Conflicts of Interest: The authors declare no conflict of interest.

\author{
Abbreviations \\ The following abbreviations are used in this manuscript: \\ CP Cerebral Palsy \\ QoL Quality of Life \\ WHO World Health Organization \\ CPUP Cerebral Palsy Follow-Up Program \\ APL Adductor-iliopsoas Lengthening \\ GMFCS Gross Motor Function Classification System \\ MP Migration Percentage \\ VDRO Varus Derotation Osteotomy of the Proximal Femur
}




\section{References}

1. World Health Organization. The World Health Organization Quality of Life assessment (WHOQOL): Position paper from the World Health Organization. Soc. Sci. Med. 1995, 41, 1403-1409. [CrossRef]

2. Michelsen, S.I.; Flachs, E.M.; Damsgaard, M.T.; Parkes, J.; Parkinson, K.; Rapp, M.; Arnaud, C.; Nystrand, M.; Colver, A.; Fauconnier, J.; et al. European study of frequency of participation of adolescents with and without cerebral palsy. Eur. J. Paediatr. Neurol. 2014, 18, 282-294. [CrossRef] [PubMed]

3. Ramstad, K.; Jahnsen, R.; Skjeldal, O.H.; Diseth, T.H. Mental health, health related quality of life and recurrent musculoskeletal pain in children with cerebral palsy 8-18 years old. Disabil. Rehabil. 2012, 34, 1589-1595. [CrossRef] [PubMed]

4. World Health Organization. The International Classification of Functioning, Disability and Health; WHO: Geneva, Switzerland, 2001.

5. World Health Organization. World bank. In World Report on Disability; WHO: Geneva, Switzerland, 2011.

6. American Public Health Association. Available online: http://www.apha.org/about-apha/ourvision/our-mission (accessed on 3 December 2020).

7. Krahn, G.; Campbell, V. Evolving views of disability and public health: The roles of advocacy and public health. Disabil. Health J. 2011, 4, 12-18. [CrossRef] [PubMed]

8. Lollar, D.; Crews, J.E. Redefining the role of public health in disability. Annu. Rev. Public Health 2003, 24, 195-208. [CrossRef] [PubMed]

9. Krahn, G.; Klein Walker, D.; Correa-De-Araujo, R. Persons with disabilities as an unrecognized health disparity population. Am. J. Public Health 2015, 105 (Suppl. S2), S198-S206. [CrossRef] [PubMed]

10. Rosenbaum, P.; Paneth, N.; Leviton, A.; Goldstein, M.; Bax, M.; Damiano, D.; Dan, B.; Jacobsson, B. A report: The definition and classification of cerebral palsy April 2006. Dev. Med. Child Neurol. 2007, 109, 8-14.

11. Hollung, S.J.; Bakken, I.J.; Vik, T.; Lydersen, S.; Wiik, R.; Aaberg, K.M.; Andersen, G.L. Comorbidities in cerebral palsy: A patient registry study. Dev. Med. Child Neurol. 2019, 62, 97-103. [CrossRef] [PubMed]

12. Bagg, M.R.; Farber, J.; Miller, F. Long-term follow-up of hip subluxation in cerebral palsy patients. J. Pediatr. Orthop. 1993, 13, 32-36. [CrossRef] [PubMed]

13. Robb, J.E.; Hägglund, G. Hip surveillance and management of the displaced hip in cerebral palsy. J. Child Orthop. 2013, 7, 407-413. [CrossRef] [PubMed]

14. Hägglund, G.; Lauge-Pedersen, H.; Wagner, P. Characteristics of children with hip displacement in cerebral palsy. BMC Musculoskelet. Disord. 2007, 8, 101. [CrossRef] [PubMed]

15. Hägglund, G.; Andersson, S.; Düppe, H.; Lauge-Pedersen, H.; Nordmark, E.; Westbom, L. Prevention of hip dislocation in children with cerebral palsy. The first ten years experience of a population-based prevention programme. J. Bone Jt. Surg. 2005, 87, 95-101. [CrossRef]

16. Hägglund, G.; Alriksson-Schmidt, A.; Lauge Pedersen, H.; Rodby Bousquet, E.; Westbom, L. Prevention of hip dislocation in children with cerebral palsy. Twenty years result of a population-based prevention programme. Bone Jt. J. 2014, 96, $1546-1552$. [CrossRef] [PubMed]

17. Alriksson-Schmidt, A.; Arner, M.; Westbom, L.; Krumlinde-Sundholm, L.; Nordmark, E.; Rodby-Bousquet, E.; Hägglund, G. A combined Surveillance Program and Quality registry improves management of childhood disability. Disabil. Rehabil. 2017, 39, 830-836. [CrossRef] [PubMed]

18. Palisano, R.; Rosenbaum, P.; Walter, S.; Russell, D.; Wood, E.; Galuppi, B. Development and reliability of a system to classify gross motor function in children with cerebral palsy. Dev. Med. Child Neurol. 1997, 39, 214-223. [CrossRef] [PubMed]

19. Palisano, R.J.; Rosenbaum, P.; Bartlett, D.; Livingston, M.H. Content validity of the expanded and revised Gross Motor Function Classification System. Dev. Med. Child Neurol. 2008, 50, 744-750. [CrossRef] [PubMed]

20. Terjesen, T. The natural history of hip development in cerebral palsy. Dev. Med. Child Neurol. 2012, 54, 951-957. [CrossRef] [PubMed] 